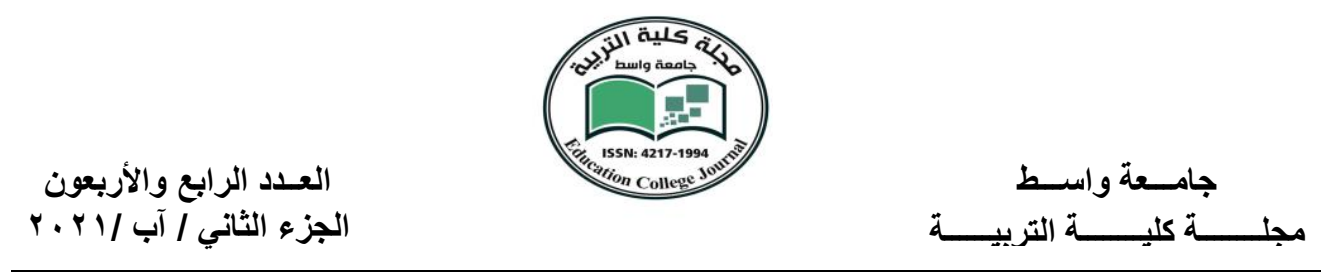

\title{
الرمز في شعر حافظ جميل
}

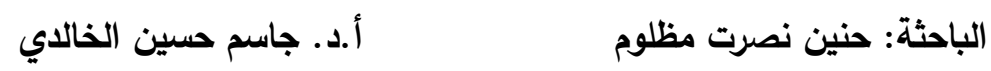

جامعة واسط / كلية التربية للعلوم الانسانية

الملخص:

تناول البحث الرمز في شعر حافظ جميل في القرن العشرين، فاللغة الرمزية تعطي الثاعر مساحة كبيرة لتعبير عن أهدافه بثكل غير مباشر ، لما تمتلكه من دلالات وايحاءات متنوعة، ويلجأ

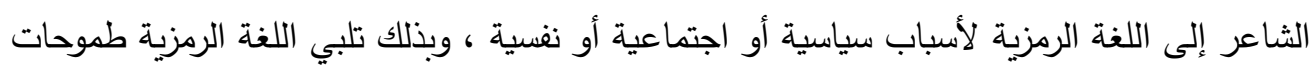

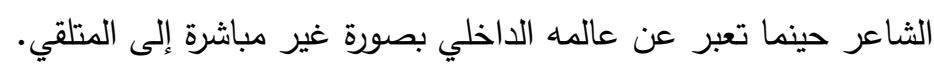

\section{The symbol in the poetry of Hafez Jameel}

\section{prof. Jassim Hussein Al-Khalidi (ph).D}

\section{And the researcher Haneen Nusrat Mazloum}

\begin{abstract}
The research deals with the artistic formation in Hafez Jameel's poetry in the twentieth century and the most important artistic manifestations and styles mentioned in his poetry, including the style of the symbol. the reasons are political, social or psychological, and thus symbolic language meets the aspirations of the poet when it expresses his inner world indirectly to the recipient.
\end{abstract}

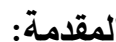

تعرضت البلدان العربية إلى هزات سياسية واجتماعية واقتصادية؛ بسبب الاحتلال والفساد

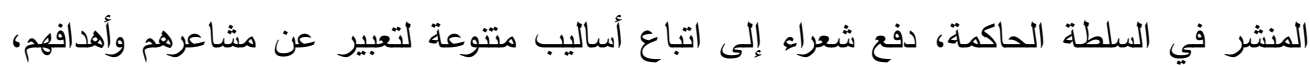

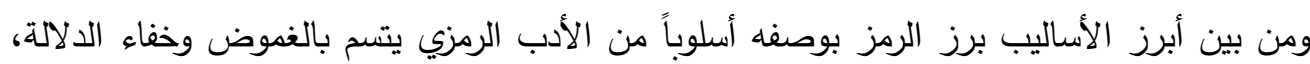

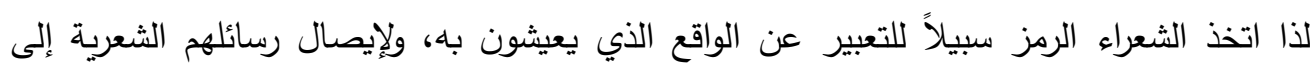

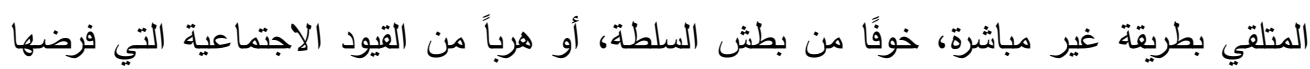

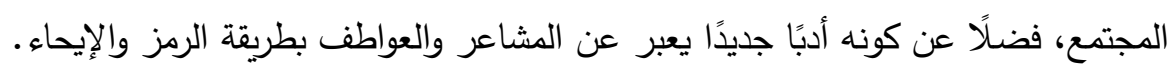


العزعد الرابع والأربعون

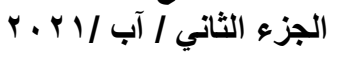

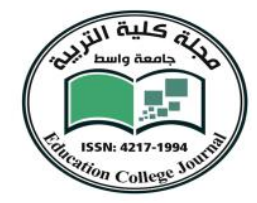

أولاً: الرمز المصطلح والمفهوم: تحنَ

تعدّ اللغة الثعريّة لغة إيحائيَّة تحوي كثيرًا من الكلمات الثريّة ذات الدلالات والإيحاءات

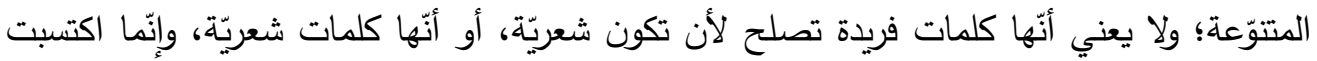

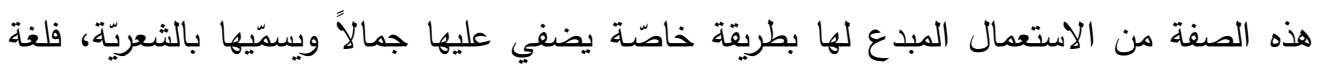

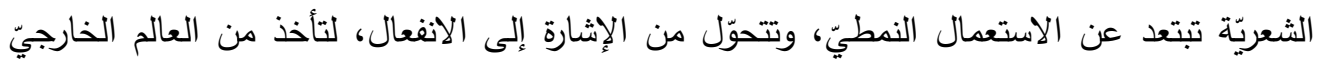

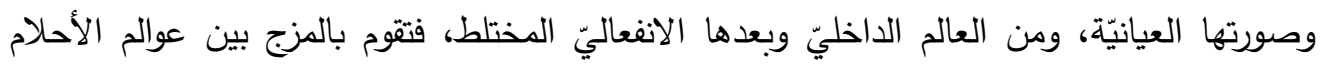

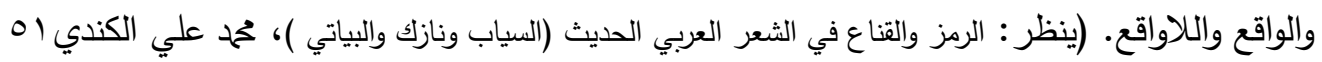

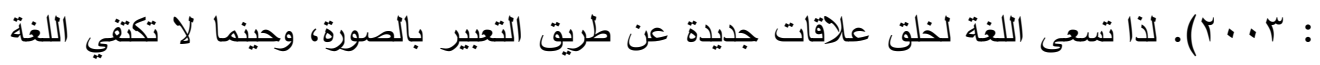

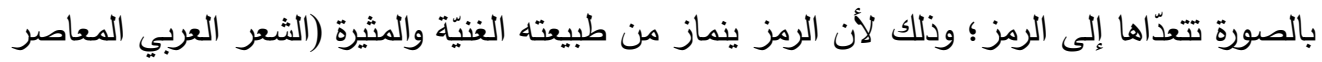

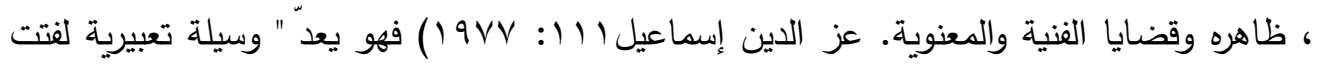

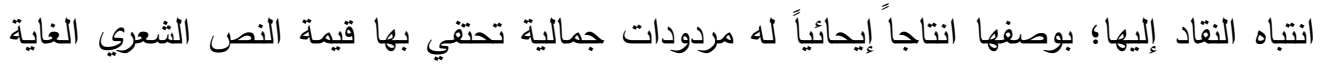

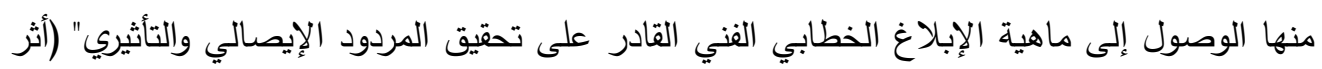

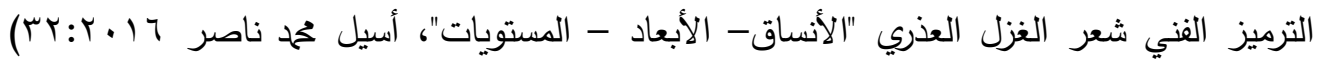

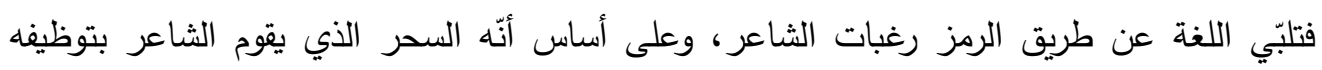

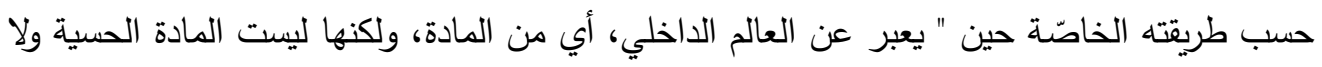

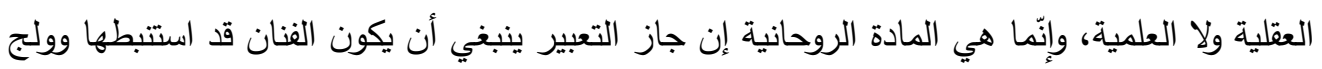

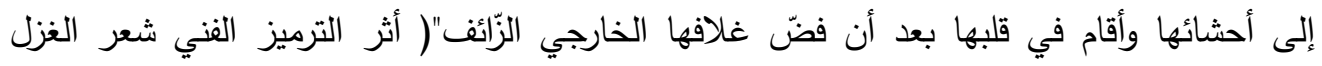

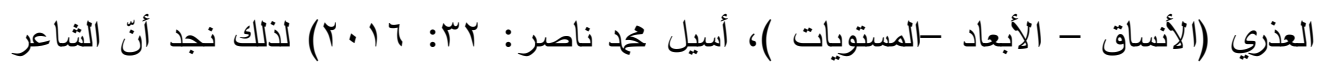

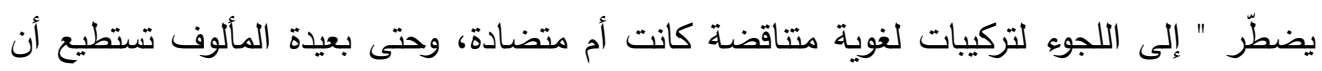

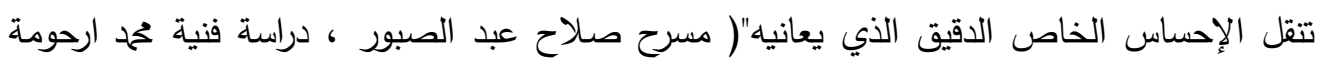

.$(199 \cdot: 10 \mathrm{~V}$

يعتمد الرمز كلّ الاعتماد على الإيحاء والإثارة، ويقوم على علاقات خاصّة يبتعد فيها عن الحسّيّة

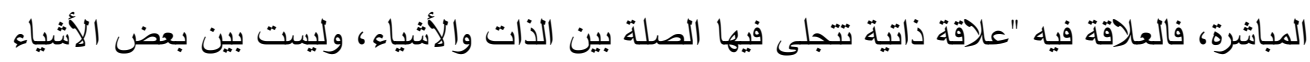

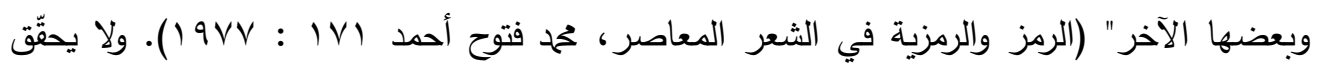

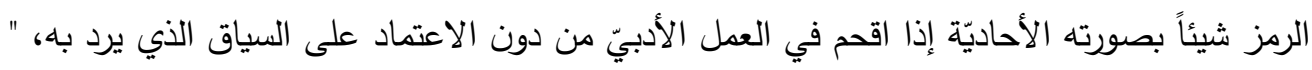

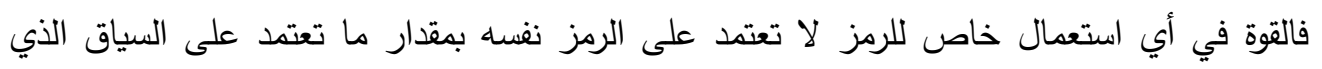

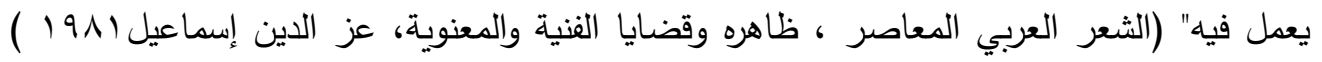


ومن أجل ذلك قد أورد الثاعر المعاصر مسألة الرمز الثعريّ، من أجل الحصول على مزيد من

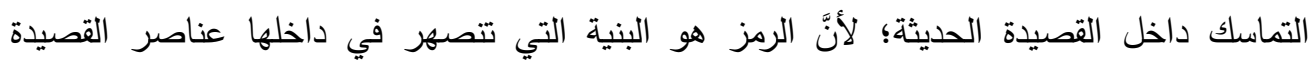

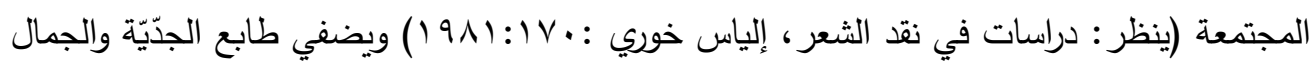

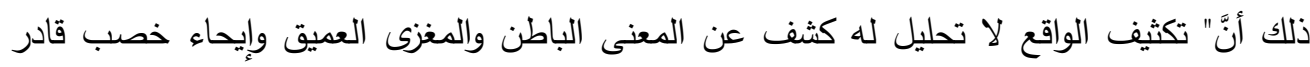

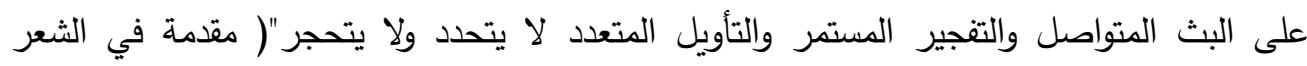

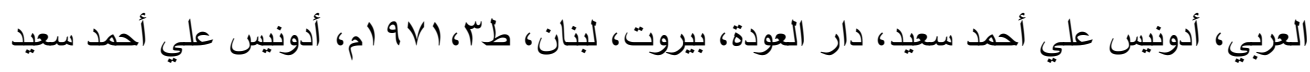

(1 T4:) 971 إنّ حقيقة ما يوحي به الرمز من إيحاءات ودلالات تكون جميعا مستمدّة فاعليّتها من جذورها

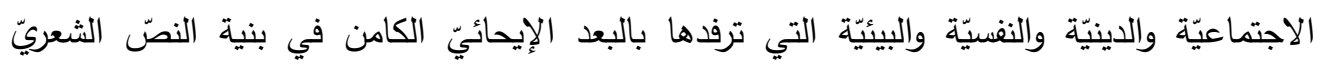

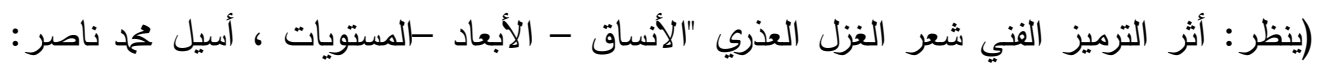

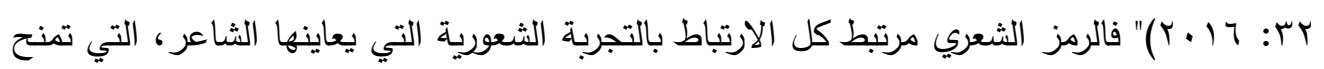

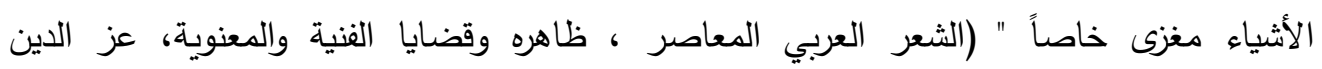

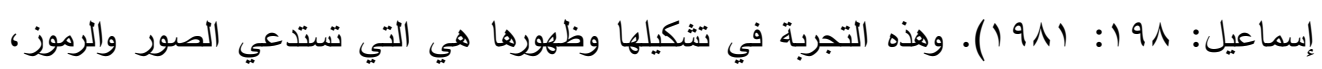

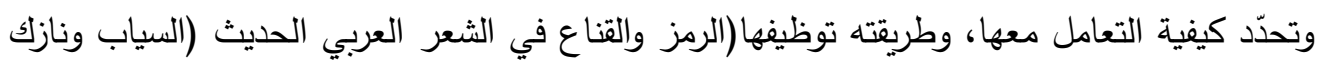

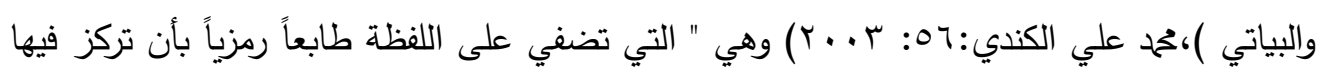

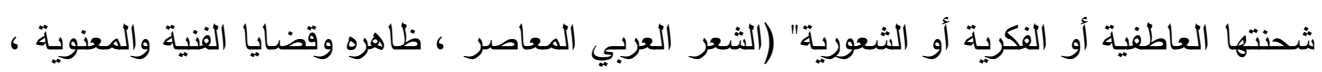

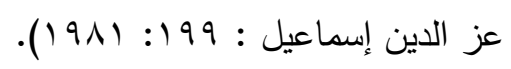

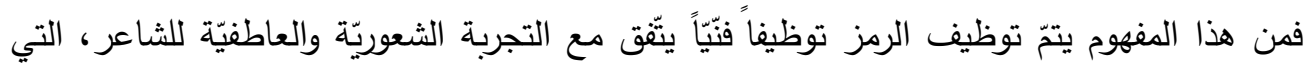

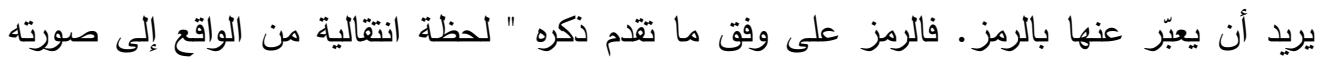

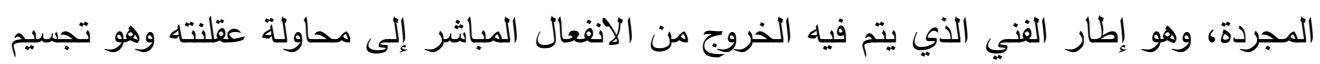

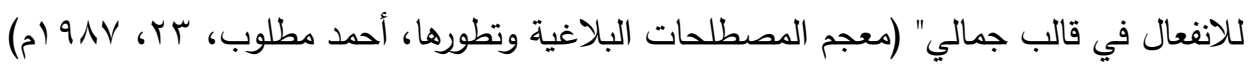
ثانياً - توظيف الرمز في المدوّنة الثعريّة لحافظ جميل : أ- رموز الطبيعة - تائا توطيف الطرمز

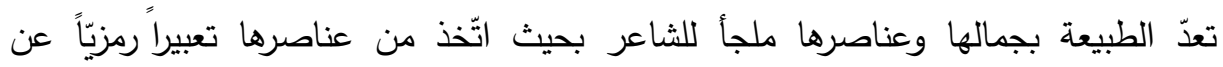

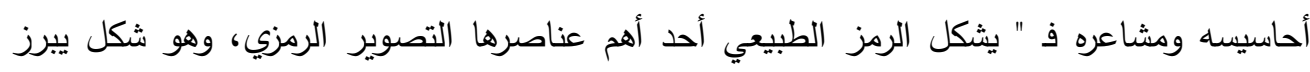

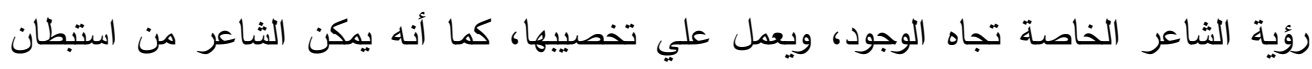

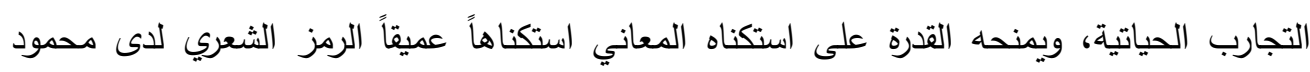




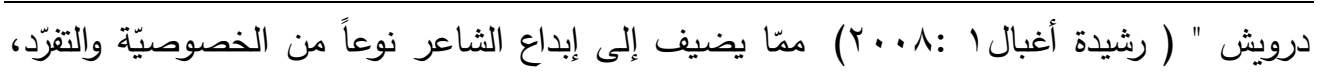

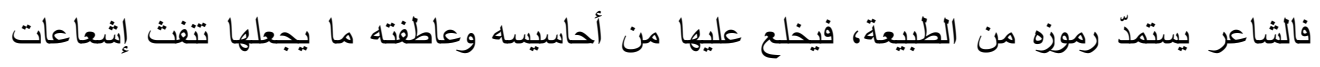

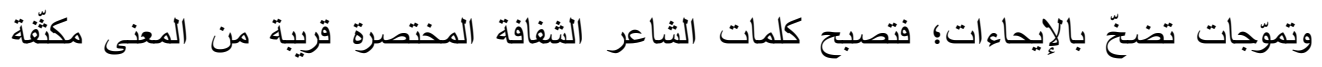

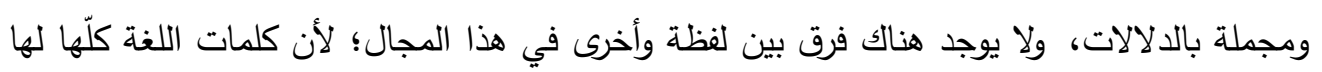

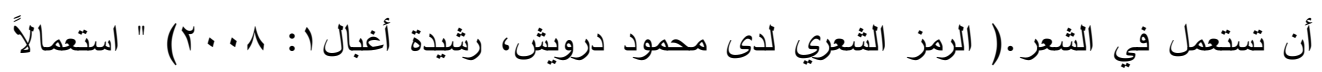

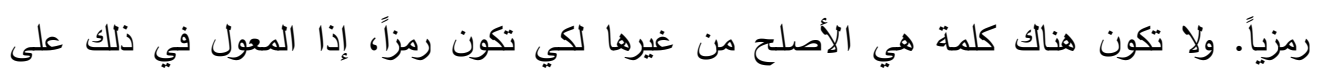

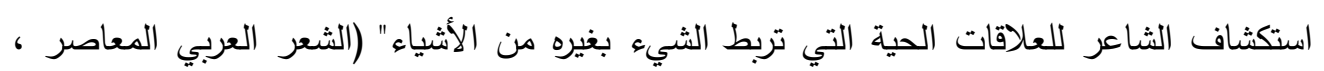

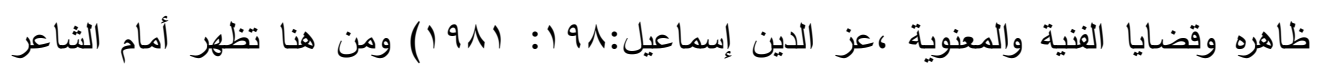

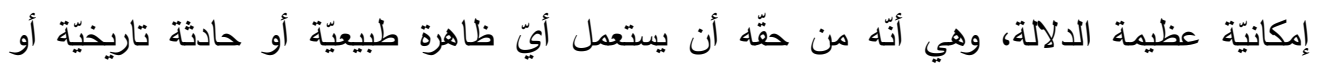

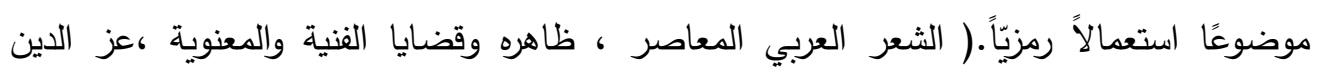

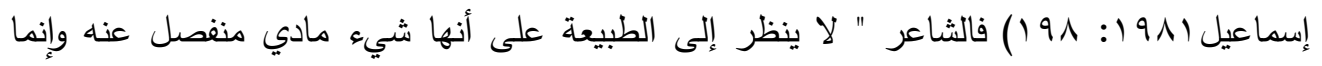

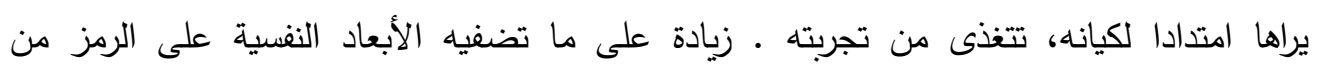

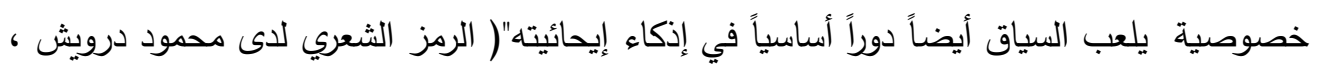

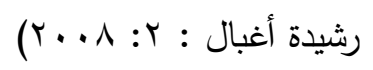

ومن أهم الرموز المستخلصة من شعر حافظ جميل :

- الموج

يثير الموج في الغالب صورة رمزيّة تدل على القوّة والعظمة، فهو من العناصر الطبيعيّة التي

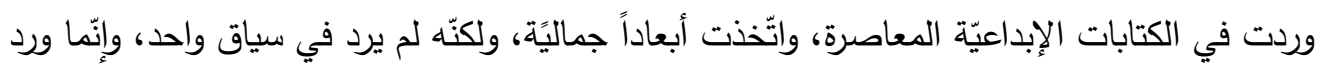

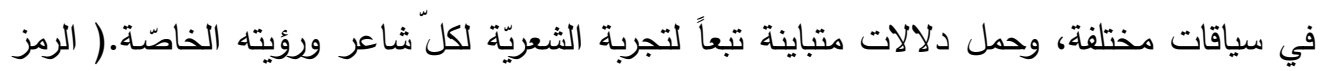

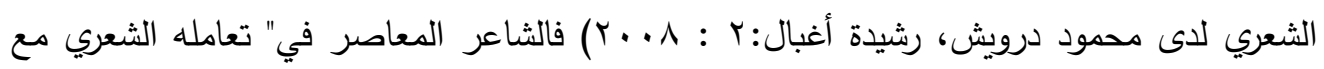

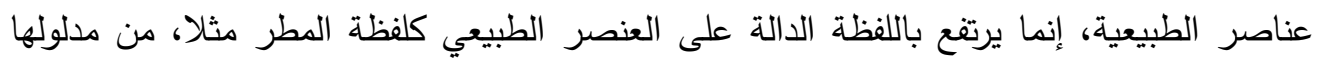

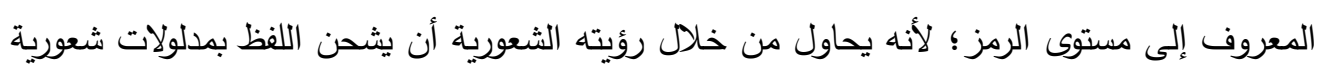

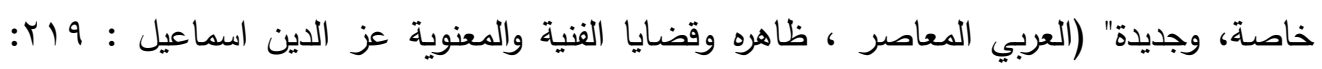

فقد استعمل الثاعر دلالة الموج في غير المعنى المتّقق عليه، بل استعمله دلالة على المرأة

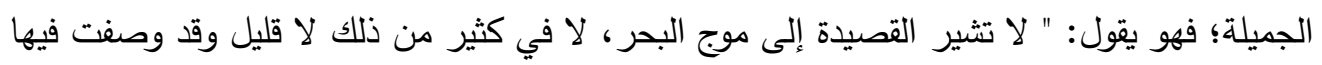


غادة حسناء، كان صدرها العاري المرمري قد أوحى لي تثبيه بالموجة وحاولت أن لا يفهم القارئ

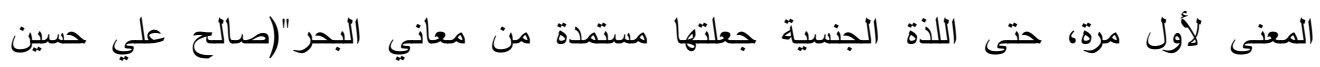

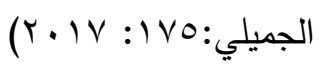

$$
\text { ويقول في قصيدة ( يا موج ) }
$$

\section{يا موج كم أَغْرِت من ظعامئ}

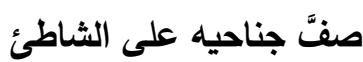

\section{يبحث عن ينبوعك الدافئ (نبض الوجدان 197 (1)}

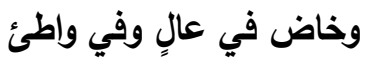

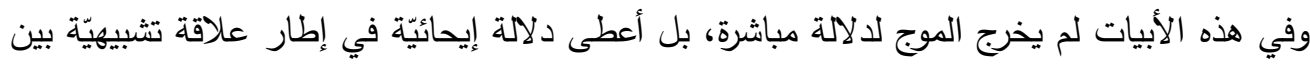

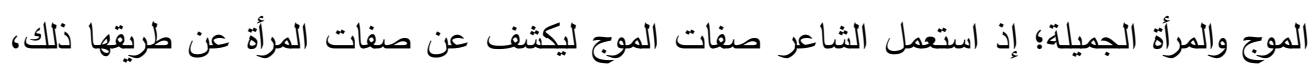

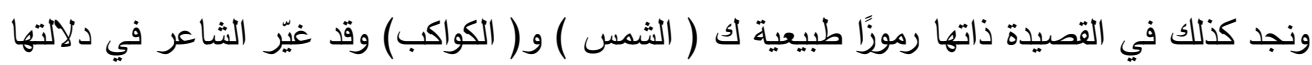

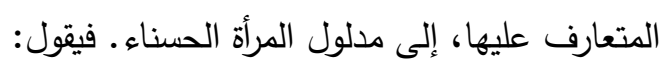

\section{كلاهما من ظماً يلهب (نبض الوجدان: 97 ())}

ولهذا كانت الرمزية عند جميل تعني الإبهام والعمل على إجهاد القارئ في الوصول إلى الى المعنى

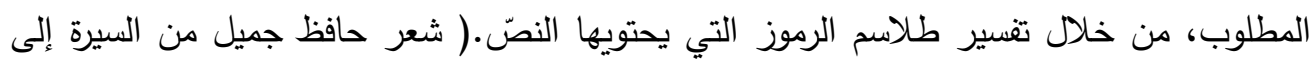

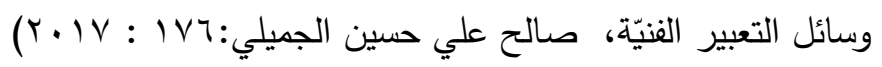

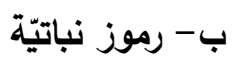
ترتكز الرموز النباتيّة التي يتفاعل معها الثاعر على محورين هما:

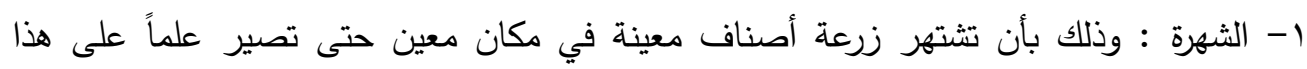
المكان ورموزاً عليه، وذلك مثل التين أو الزيتون كرموز دالة على لبنان بالثين بالشهرة.

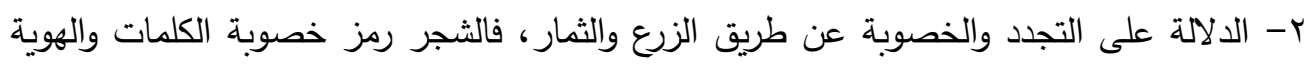

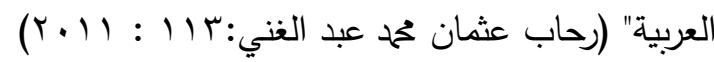

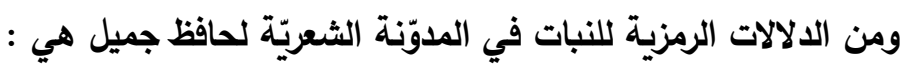

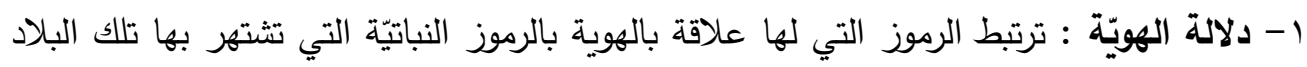

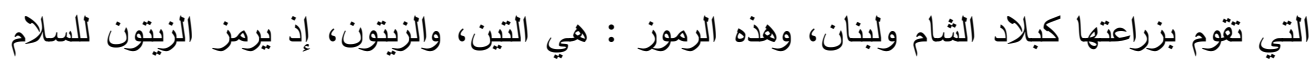


منذ أن حملت حمامة النبيّ نوح (عليه السلام) غصن الزيتون للدلالة على أنّ السلام قد حلّ في تلك الكّاء

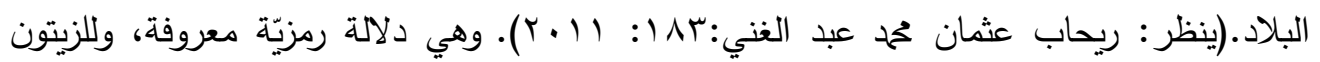

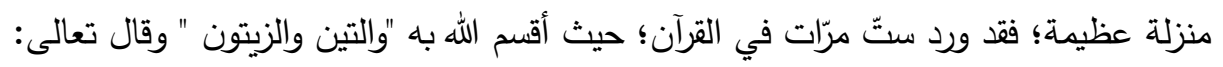

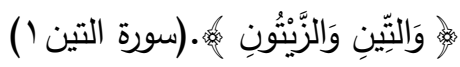

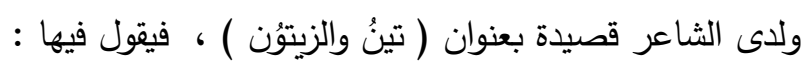

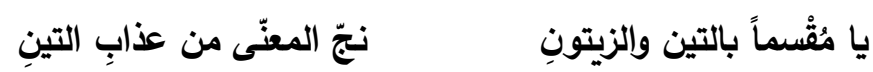

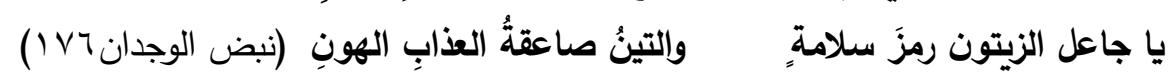

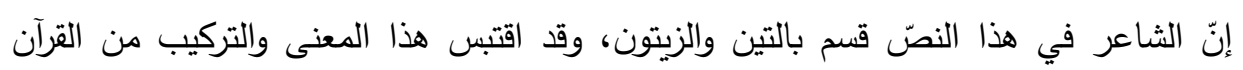

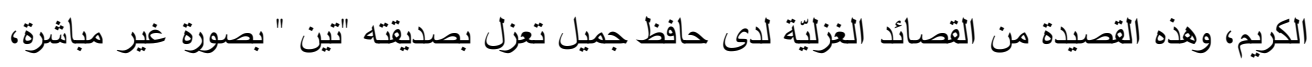

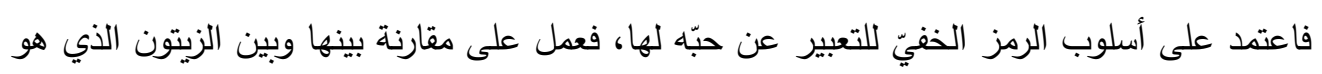

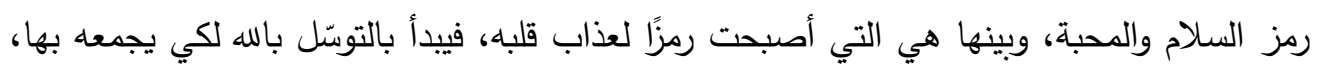
وأن يعطف عليه ويخلّصه من هذا العذاب.

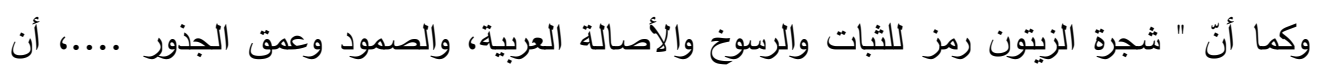

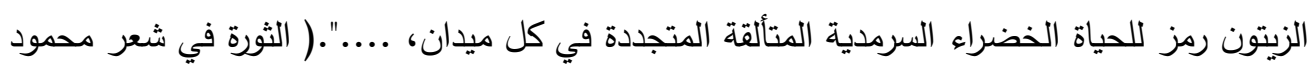

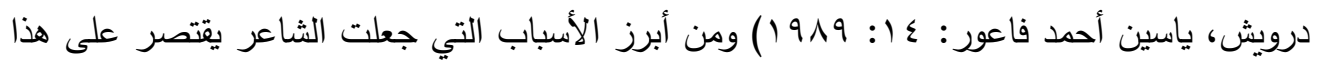

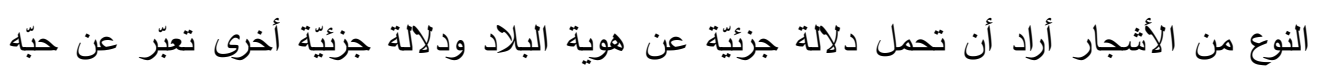
لآنسة اسمها (تين). من النماذج التي تحمل دلالة على هوية البلاد قصيدة بعنوان "تين الثام " لأل لا تطرف العينُ منها غيرَ مائسة على أَربكةِ مخضودٍ من الَّلين

يا غارس ( التين ) لا تخدعك حاليةً

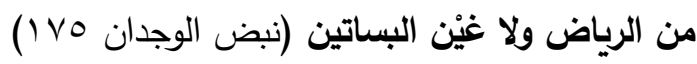

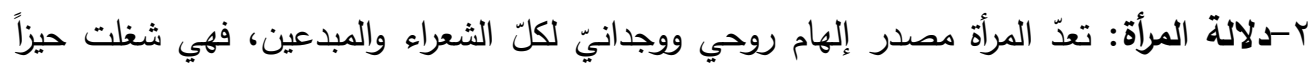

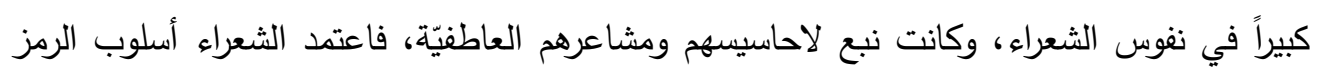

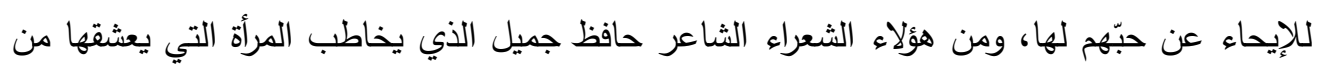

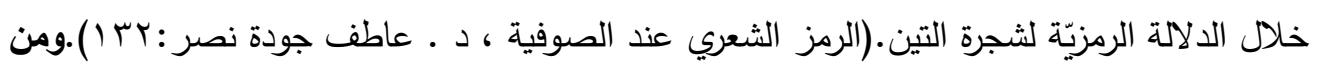

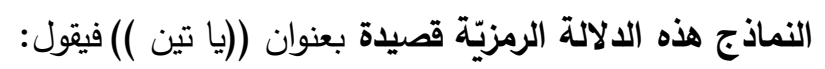




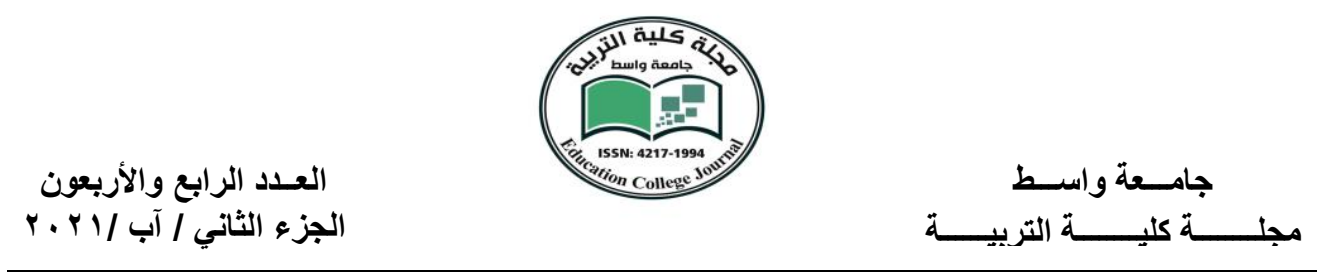

يا تين يا توت يا رمّان يا عنبُ

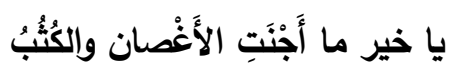

\section{يا مشتهى كلّ نفسٍ مسَّها السَّب}

يا برئ كلّ فواد شفَّه الوصب (نبض الوجدان 07 (1) )

ونلحظ أنّه اعتمد أسلوب التكرار لكلمة (التين ) للكثف عن هويّة محبوبته ومقدار حبّه لها، فضلًا

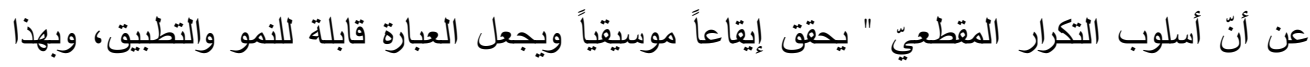

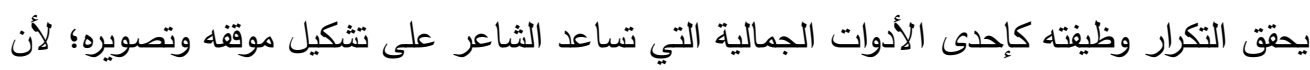

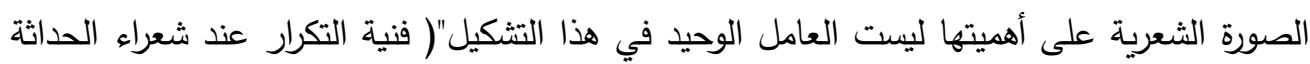

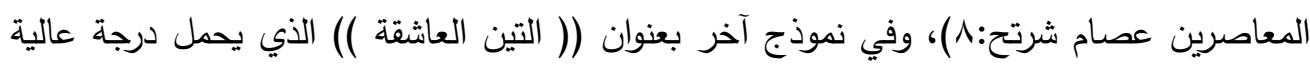

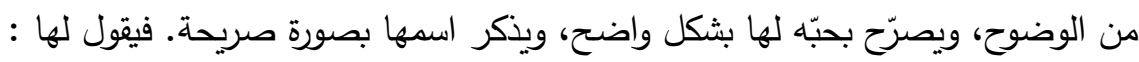

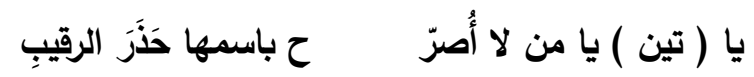

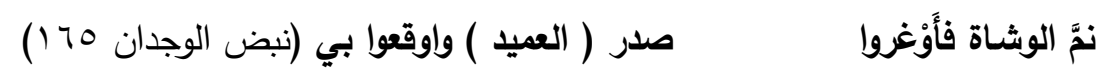

ج- رموز حيوانية (الطير)

من دلالات الطير أنّه يشير إلى السلام والحريّة، ومن دلالاته أيضاً يشير إلى الانطلاق وكسر

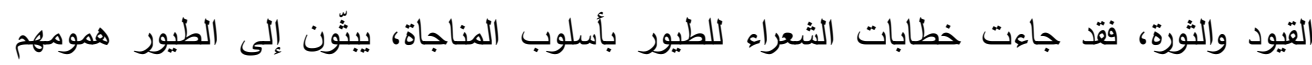

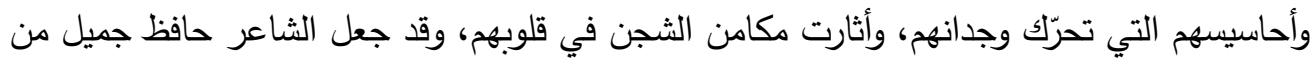

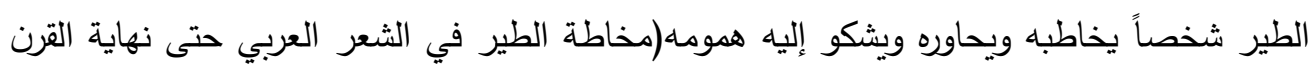

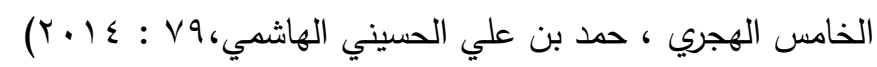

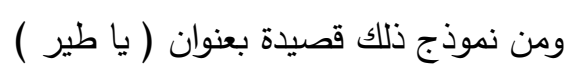

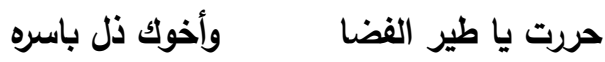

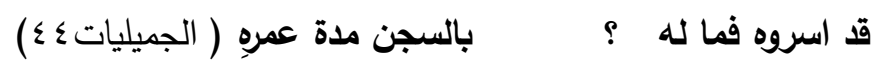

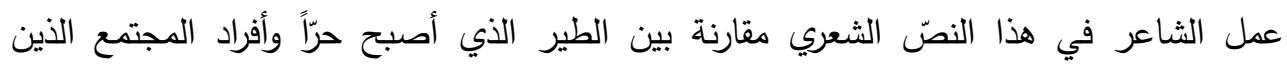

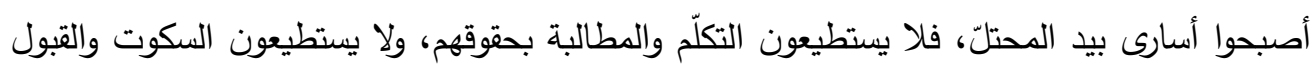

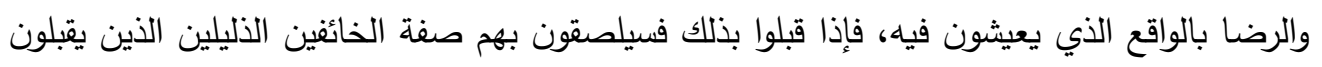

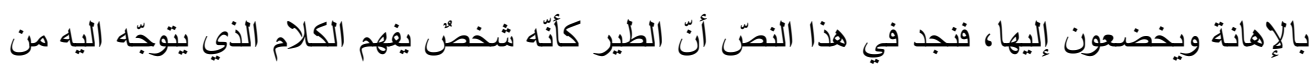
قبل الثاعر الذي يثكو همومه وأحزانه إلى الطير . 
استعمل الثاعر الرموز الثُريّة؛ لأنها تتاسب الظروف التاريخيّة والاجتماعيّة التي كان يعيش بها

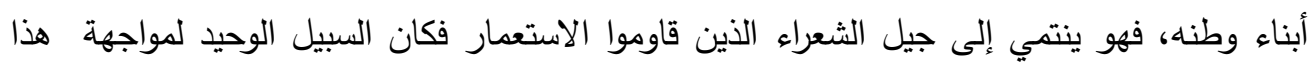

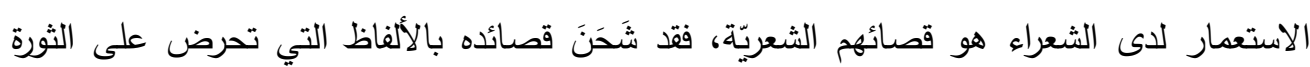

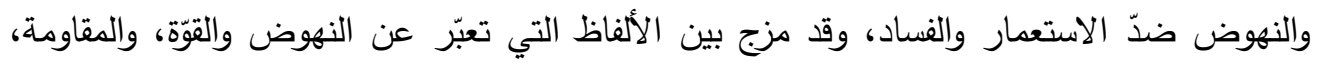

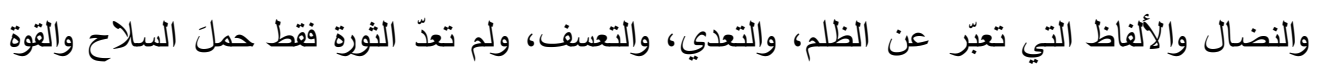

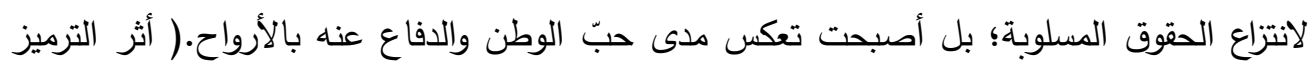

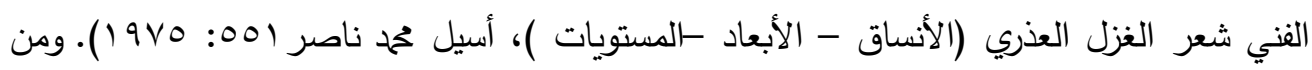

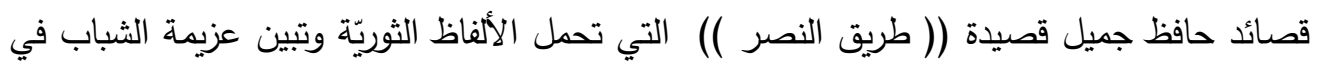
تحرير البلاد، ويقابلون الموت بكل شجاعة وعزيمة؛ فيقول فيها: كتائب من مغاوير اذا اندفعوا للموت هزوا كيان الجحفل اللجبٍ (احلام الدوالي: ؟ ؛ ( ) )

الخاتمة:

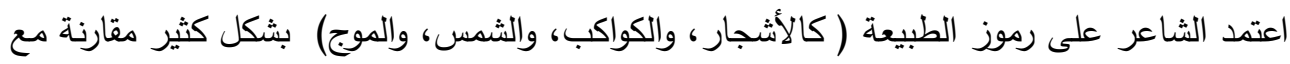

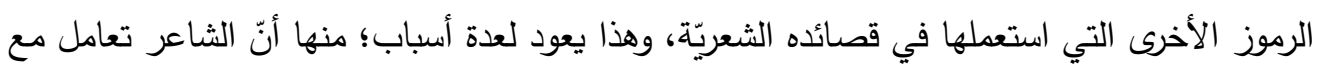

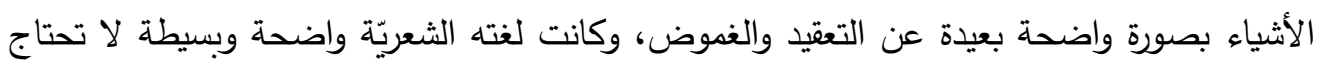

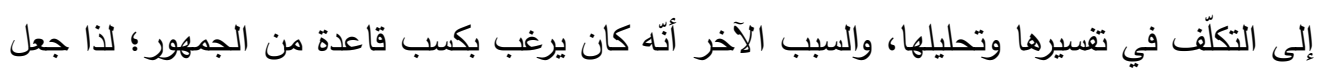

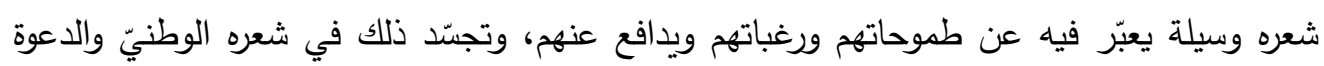

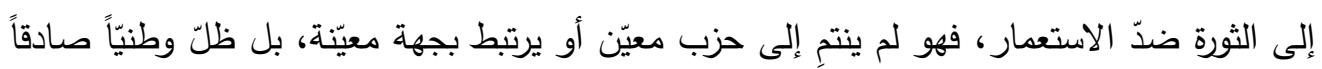
خالصاً لوطنه وأبناء شعبه. 

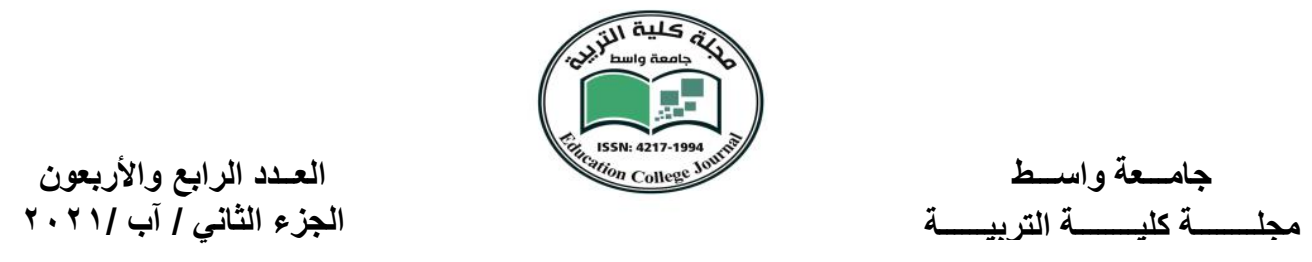

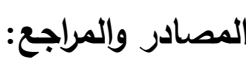

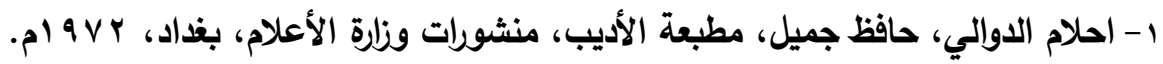

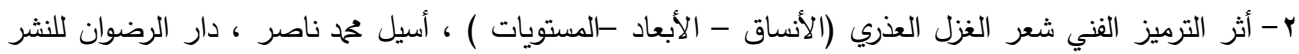

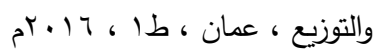

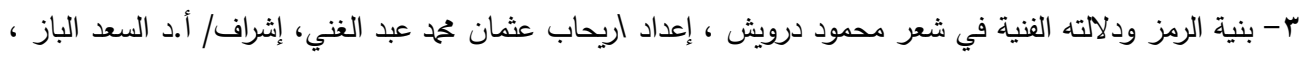

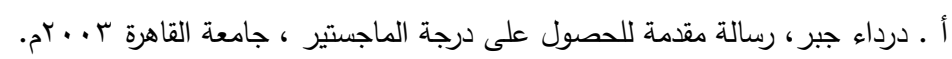

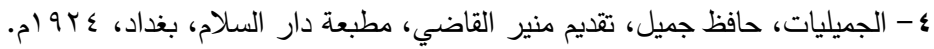

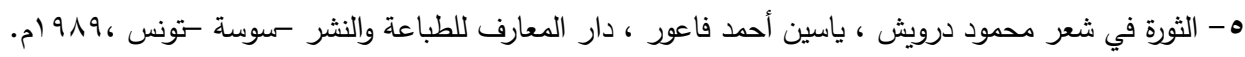

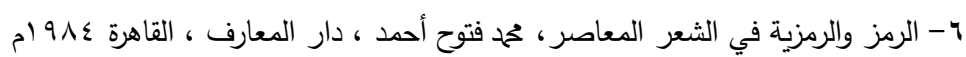

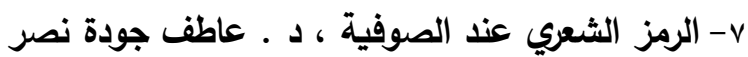

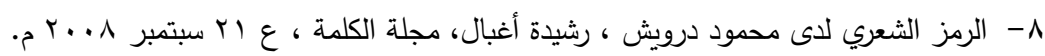

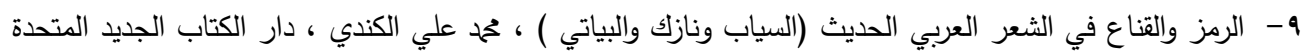

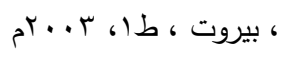

• 1-شعر حافظ جميل من السيرة إلى وسائل التعبير الفنيّة، دراسة نقدية، صالح علي حسين الجميلي، دار المنهل، $r \cdot I V$

11- الثعر العببي دراسات المعاصر ، ظاهره وقضايا الفنية والمعنوية ، عز الدين إسماعيل ، دار العودة ، بيرون،طب . 1911 1،

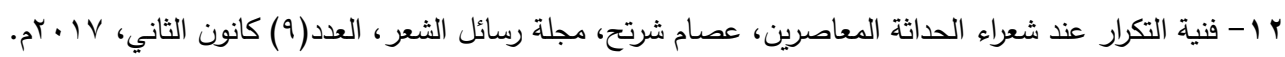

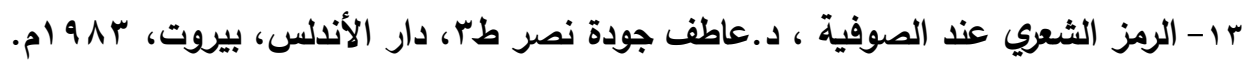

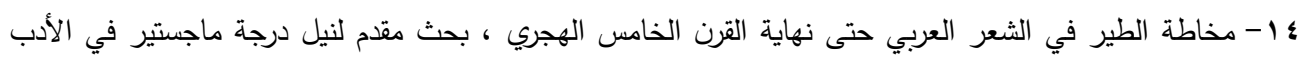

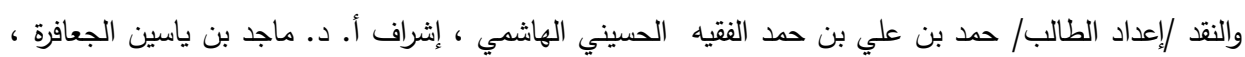

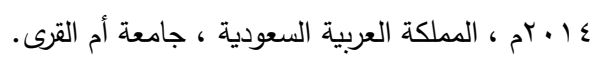

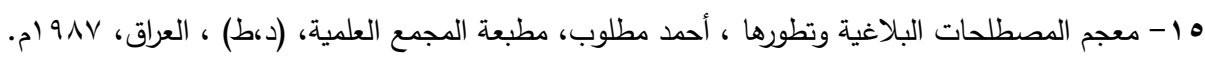

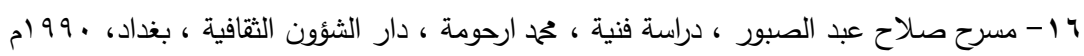
IV

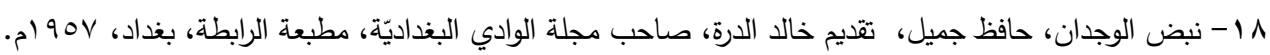

\section{Sources and references:}

1- The Impact of Artistic Coding: Virgin Spinning Poetry (Styles - Dimensions - Levels), Aseel Muhammad Nasser, Dar Al-Radwan for Publishing and Distribution, Amman, 1 st Edition,2016

2 - The structure of the symbol and its artistic significance in Mahmoud Darwish's poetry, prepared by Rehab Othman Muhammad Abdul Ghani, supervised by Prof. Al-Saad Al-Baz, a. Dr. Robe Gabr, a thesis submitted for obtaining a master's degree, Cairo University 
3 -The revolution in the poetry of Mahmoud Darwish, Yassin Ahmed Faour, Dar Al Maaref for Printing and Publishing - Sousse - Tunis, 1989AD

4- Studies in Poetry Criticism, Elias Khoury, Dar Ibn Al-Rushd, Beirut, 2nd Edition, 1981AD

5- Symbolism and Symbolism in Contemporary Poetry, Muhammad Fattouh Ahmed, Dar Al Ma'arif, Cairo 1984 AD

6- Mahmoud Darwish's poetic symbol, Rachida Aghbal, Al-Kalima magazine, No. 21September 2008

7-Symbol and Mask in Modern Arabic Poetry (Al-Sayyab, Nazik and Al-Bayati), Muhammad Ali Al-Kindi, The New Book United House, Beirut, 1st Edition, 2003AD

8- Contemporary Arabic Poetry, Its Appearance and Technical and Moral Issues, Izz al-Din Ismail, Dar al-Awda, Byron, ־rd edition, 1981AD.

9- Bird stitching in Arabic poetry until the end of the fifth century AH, research presented for a master's degree in literature and criticism / prepared by the student $\backslash$ Hamad bin Ali bin Hamad Al-Faqih Al-Husseini Al-Hashemi, supervised by Prof. Dr.. Majid bin Yassin AlJaafra 2014, Kingdom of Saudi Arabia, Umm Al-Qura University

10- A Dictionary of Rhetorical Terms and Their Evolution, Ahmed Matlab, Al Majma' Scientific Press, (D, I), Iraq, 1987 AD, Volume 3

11- Salah Abdel-Sabour Theatre, Artistic Study, Muhammad Arhouma, House of Cultural Affairs, Baghdad, 1990 AD

12- Introduction to Arabic Poetry, Adonis Ali Ahmed Saeed, Dar Al-Awda, Beirut, Lebanon, 3 rd edition, 1971 AD.

\section{Poetry books:}

1-Ahlam Al-Dawali, Hafez Jamil, Ministry of Information - Baghdad, Al Adeeb AlBaghdadi Press, 1972.

2-Areej Al-Hamael, Hafez Jamil, (D, I), Publications of the Ministry of Information Republic of Iraq, (D, T(

3-Aesthetics, Hafez Jameel, presented by A. Dr.. Saleh Hussein al Jumaili, Dar al-Salaam Press, Iraq - Mosul, Volume 1, 2014.

4-Nabd Al-Wujdan, Hafez Jamil, Al-Rabita Press, 1st Edition, Baghdad, 1957 AD. 